\title{
Correction to: Natural anti-proliferative agent loaded self- microemulsifying nanoparticles for potential therapy in oral squamous carcinoma
}

\author{
Shital C. Patil ${ }^{1} \cdot$ Amol A. Tagalpallewar ${ }^{1} \cdot$ Chandrakant R. Kokare $^{1}$ \\ Published online: 17 April 2020 \\ (c) The Korean Society of Pharmaceutical Sciences and Technology 2020
}

\section{Correction to: \\ Journal of Pharmaceutical Investigation \\ (2019) 49:527-541 \\ https://doi.org/10.1007/s40005-018-00415-x}

The authors want to change the ethical approval statement in the original publication.

The correct statement is indicated below.
Ethical approval Ex vivo permeation study for the developed formulation was approved by the 'Institutional Animal Ethics Committee' regulated by CPCSEA of Sinhgad Institute of Pharmacy, Pune-411041 (Protocol No. SIOP/IAEC/2018/02/101).

Publisher's Note Springer Nature remains neutral with regard to jurisdictional claims in published maps and institutional affiliations.
Chandrakant R. Kokare

kokare71@rediffmail.com

1 Department of Pharmaceutics, Sinhgad Technical Education Society's, Sinhgad Institute of Pharmacy (Affiliated to Savitribai Phule Pune University), Narhe, Pune, Maharashtra 411041, India 